\title{
Noise assessment inside the Greater Cairo Underground second-line Metro
}

\author{
MOSTAFA E ALY \\ Mechanical Engineering Department, National Research Center, Dokki, Cairo, \\ Egypt \\ e-mail: mostafaealy@yahoo.com
}

MS received 3 August 2004; revised 18 November 2004

\begin{abstract}
Underground metro trains, which connect different terminals of big crowded cities, are the best means of public transportation. The metro is environmentally friendly because the trains are electrically driven and so do not emit chemical air-pollutants. The number of people using the Greater Cairo Underground Metro approaches two million per day, beside about one thousand workers in the different activities related to the metro. Metro users and workers complain about the high noise levels emitted by metro units travelling in the tunnels, especially at the turns, the entrance of tunnels and at stations while braking.

Exposure to high noise levels for a long time causes many health hazards: either auditory, such as temporary and permanent hearing loss, or extra-auditory such as effects on the cardiovascular system, blood pressure, heart and respiratory rates, central nervous system. Noise also leads to stress problems such as lack of concentration, leading to accidents. Noise has adverse effects on psychological, biological, immunological and hormonal systems of the body.

Due to the above mentioned reasons, suggestion has been made to start this research to assess and diagnose these problems, and to find the proper methods for early detection and proper management of these health hazards; in addition to the engineering solutions for the noise problem. Measurements of noise levels have been made inside the units while travelling and outside the units at the stations platforms to evaluate the noise problem and to suggest some kind of solutions to the problem. The calculations of different noise indices have been made and compared with international criteria and national laws. The comparison shows that the noise levels are clearly unacceptable, for indices $L_{1}, L_{99}$, and LNP, both inside the metro units and outside the units at station platforms along the passage.
\end{abstract}

Keywords. Underground metro; tunnels; noise pollution; occupational health; subway trains.

\section{Introduction}

Noise is considered a basic form of physical air pollution. It is a significant cause of hearing loss, in addition to many other adverse effects on health. Noise pollution is considered an 
important occupational health problem, as it especially affects people in the prime of life when their productivity, social and family responsibilities are greatest. Recognition and careful assessment of noise exposure are the foundation on which preventive measures and treatment are based.

Noise can be defined as unwanted sound. Exposure to high levels of noise for a long time can result in first partial, then complete hearing loss. The effect of noise as a health hazard is due to mechanical damage to the inner ear. Noise produces psycho-physiological deregulation which can be either indirectly, due to annoyance, or directly caused by stress to the vegetative-hormonal system (Maschke \& Harder 1998).

Exposure to high levels of noise can result in elevation of cholesterol, triglycerides, LDL, HDL, VLDL, and apolipoprotein-A (Nagat \& Risk 2001), and elevation of blood pressure and changes in patterns (Nagat \& Risk 1995).

Nine key groups of health effects believed to be influenced by noise: sleep disturbance, performance problems, cardiovascular diseases, fetal and children health, psychiatric disorders, annoyance, health effects due to noise and other stresses and endocrine disorders (Stansfeld 1998). Some researches have identified some interesting and novel findings in the form of neurodegenerative diseases and cardiovascular diseases associated with heart rate variability (Savitz et al 1999).

The Greater Cairo Underground Metro (GCUM) project consists of two lines. The first one goes from El-Margg at the north end of Cairo to Helwan at the southern-most end of Cairo, the second one stretches from Shoubra El-Kheimah at the El-Qualiubia Governorate (part of the Greater Cairo province), to El-Giza Suburban at the Giza Governorate (also part of the Greater Cairo province). This study deals with the second line only, because its passage is mostly underground for about $20 \mathrm{~km}$ from the El-Gamaah station to the El-Mezallat station.

Figure 1 shows the number of passengers using the second line of the GCUM in millions/day. The figure shows that the number of passengers has increased successively with the years. This increase is due to the increase of metro units from 6 to 8 units per train, and also due to the increase of passage length from the Mubarak station to Sadat station and to

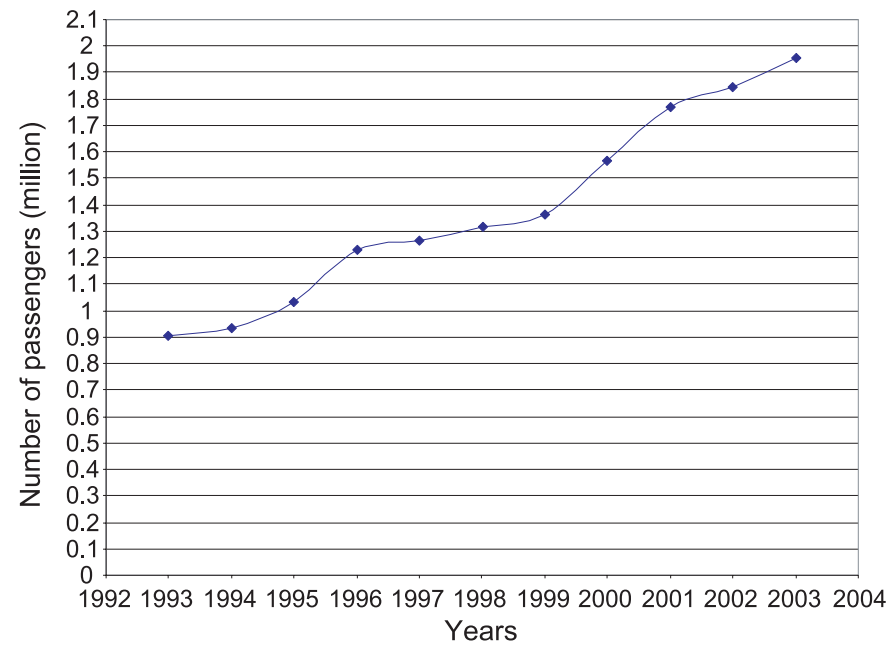

Figure 1. Statistical analysis of number of passengers using the second line of the Greater Cairo Underground Metro in million/day with years. 
El-Gamaah and then to Giza Suburban station. This increase in line length means increase in the number of passengers who come from the three Governorates (Cairo, Giza, and Qualiubia) and also those coming from upper and down Egypt by train. It is obvious from the figure that the number of passengers approaches two million passengers/day, in addition to about one thousand workers in the GCUM, suffering from exposure to high noise levels.

\section{Measurements}

Measurements of the equivalent sound level in $\mathrm{dBA}, L_{e q}$, have been made during the hours starting from 07:00 am to 09:00 pm at the platform of each station inside the tunnel, and inside the metro units between stations, using the Precision Integrating Sound Level meter B \& K 2230 and B \& K mediator 2238 for a whole month. Measurements were made for the stations from El-Gamaah to El-Mezallat, and were used to calculate some noise indices for comparison with the international standards of noise exposure (Alexandre et al 1975).

\section{Results and discussion}

Calculations of the percentile noise indices $L_{1}, L_{10}, L_{50}, L_{90}, L_{99}$, and the Noise Pollution Index (LNP) were made through making the cumulative curve for each level VS time curve, which gives the percentile indices, $L_{1}, L_{10}, L_{50}, L_{90}$, and $L_{99}$ directly from the curve.

- $L_{1}$ represents the maximum noise events, like the fast noise events like train air siren, which takes about $1 \%$ of the measuring period.

- $L_{10}$ is the peak noise index, which represents the level exceeded for $10 \%$ of the measuring period.

- $L_{90}$ is the noise climate index, which represents the noise level exceeded for $90 \%$ of the measurement period.

- $L_{99}$ is the background noise level, which represents mostly the lowest noise level during the measurement period.

- $L_{e q}=10 \log _{10}(1 / t) \int_{0}^{t}\left[P(e) / P_{\text {ref }}\right]^{2} \mathrm{~d} t \mathrm{~dB}$ (Hasting \& Peacock 1975) where, $P_{e}$ is the measured effective pressure of the particular sound wave in units of force per square length, $P_{\text {ref }}$ is the reference effective pressure.

- The noise pollution index (denoted by LNP) can be calculated from the relation,

$$
\mathrm{LNP}=L_{e q}+2 \cdot 56 \sigma,
$$

where $\sigma=$ the standard deviation of the readings (Don \& Rees 1985).

The criteria adapted by the US Department of Housing and Urban Development for $L_{1}, L_{99}$ and LNP from noise sources other than aircraft have been classified in table 1 (HUD 1971, 1985).

Figure 2 shows the maximum noise events index $\left(L_{1}\right)$ calculated from the measurements of noise levels, measured in $\mathrm{dBA}$, inside the metro units between the stations compared with the criteria adopted by the US. Department of Housing and Urban Development (USHUD). It is obvious from the figure that the maximum noise event index $L_{1}$ inside the units is very high and exceeds the limit of the clearly unacceptable range which is $>86 \mathrm{dBA}$. The calculated 
Table 1. USHUD criteria for $L 1, L 99$ and LNP.

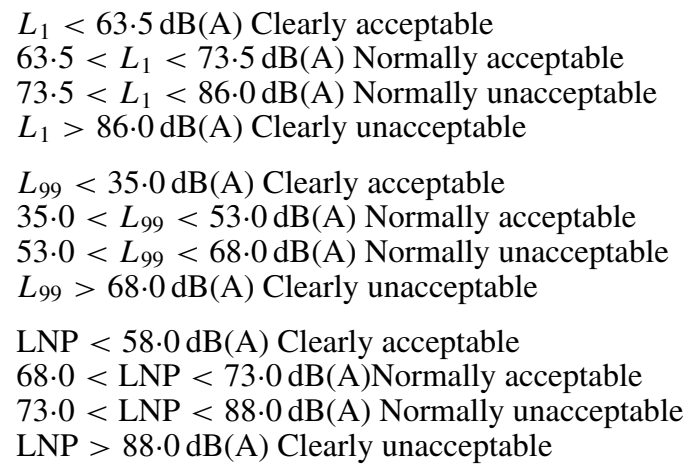

$L_{1}$ ranges from 87.8 to $102.5 \mathrm{dBA}$., so it exceeds the limit by about 1.5 to $16.5 \mathrm{dBA}$. The highest value of $L_{1}$ was noted between El-Gamaah and El-Behoos stations, this is due to the tunnel entrance and the sharp turn of $90^{\circ}$, which increases the slip between the wheels and the rails, which in turn increases the noise emission.

Figure 3 shows the maximum noise events index $\left(L_{1}\right)$ outside the train units at the station platforms calculated from the measurements of noise levels, measured in $\mathrm{dBA}$, and compared with the criteria adopted by USHUD. The sources of noise at the platforms are the aerodynamic and mechanical noises of the train, the train siren, the brakes when applied, the passengers themselves and the attention signal sound systems. It is clear from the figure that the maximum

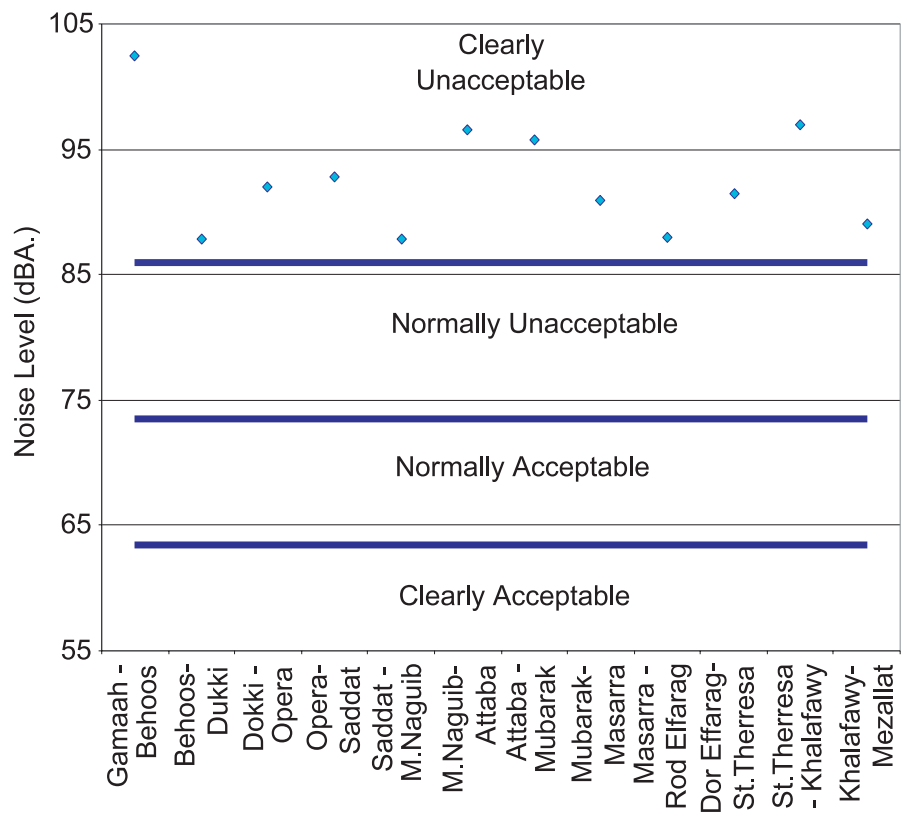

Figure 2. Maximum noise level $\left(L_{1}\right)$ inside the metro units compared with the criteria for $L_{1}$. 


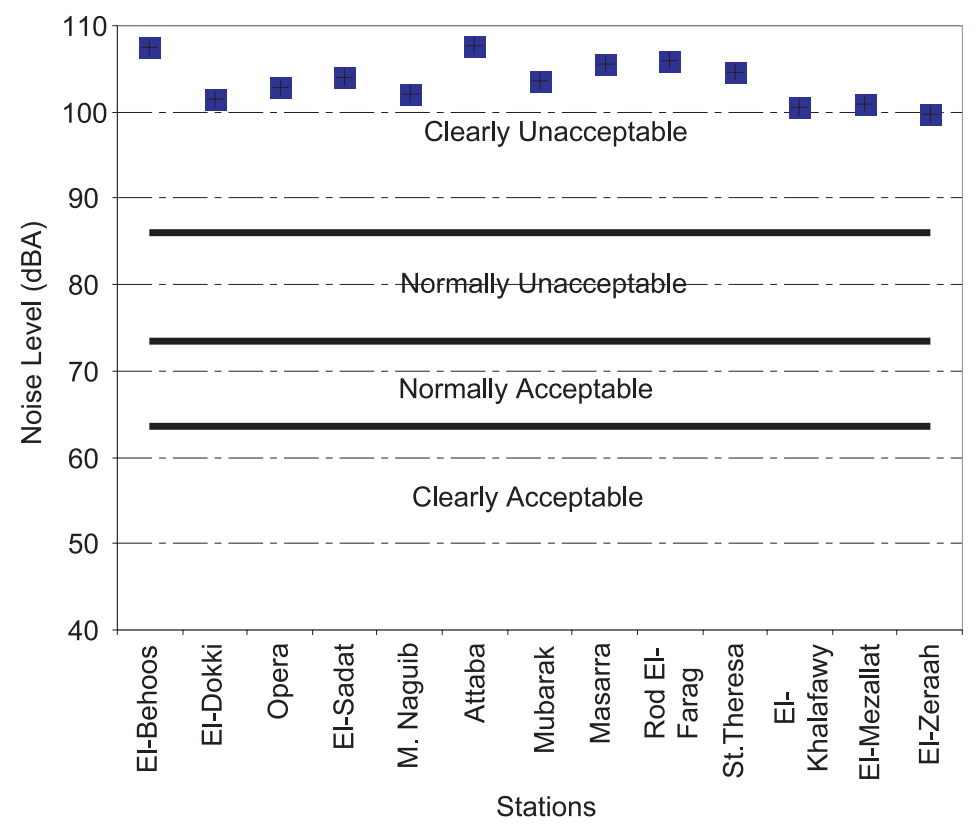

Figure 3. Maximum noise level $\left(L_{1}\right)$ outside the metro units compared with the criteria for $L_{1}$.

noise events index $\left(L_{1}\right)$ at the 2nd line of the GCUM station platform is between 100.6 dBA at the El-Khalafawy station and $107.65 \mathrm{dBA}$ at the El-Attaba station. $L_{1}$ Values at all the stations are in the range of clearly unacceptable according to the USHUD criteria. The main source of noise at El-Attaba station is the use of the train siren, because this station lies between two turns and the passengers waiting at the platform cannot see the arrival of a train, hence the drivers alert them by the siren. This station is also one of the most crowded stations (about one million passengers/day) because it is at the city centre.

Figure 4 shows the background noise index $\left(L_{99}\right)$ calculated from the measurements of noise levels measured in $\mathrm{dBA}$ inside the metro units between the stations, and compared with the criteria adopted by USHUD. It is clear from the figure that the background noise index $L_{99}$ inside the units varies from $68 \mathrm{dBA}$ between Masarra and Rod El-Farag stations to $77.5 \mathrm{dBA}$ between Opera and Sadat stations. The comparison shows that the background noise index $L_{99}$ is in the range of clearly unacceptable according to the criteria adopted by USHUD for all the underground passage of the metro. The background noise sources are mostly the interaction between the train and the air around it and between the train and tunnel walls, called aerodynamic noise, and the interaction between the train wheels and the rails, called mechanical noise. The increase in background noise is due to the increase of mechanical noise, which also rises due to the increase of unit speed.

Figure 5 illustrates the background noise index $\left(L_{99}\right)$ calculated from the measurements of noise levels in dBA outside the metro units at station platforms compared with the criteria adopted by USHUD. It is obvious from the figure that the background noise index $L_{99}$ outside the units at the platforms varies from $71.6 \mathrm{dBA}$ at El-Khalafawy station to $82 \mathrm{dBA}$ at ElBehoos station. The comparison shows that the background noise index $L_{99}$ at all the stations inside the tunnel is in the range of clearly unacceptable according to the criteria adopted by USHUD. The main sources of background noise are the application of brakes, the sound systems at the platforms and the noise of the passengers themselves. 


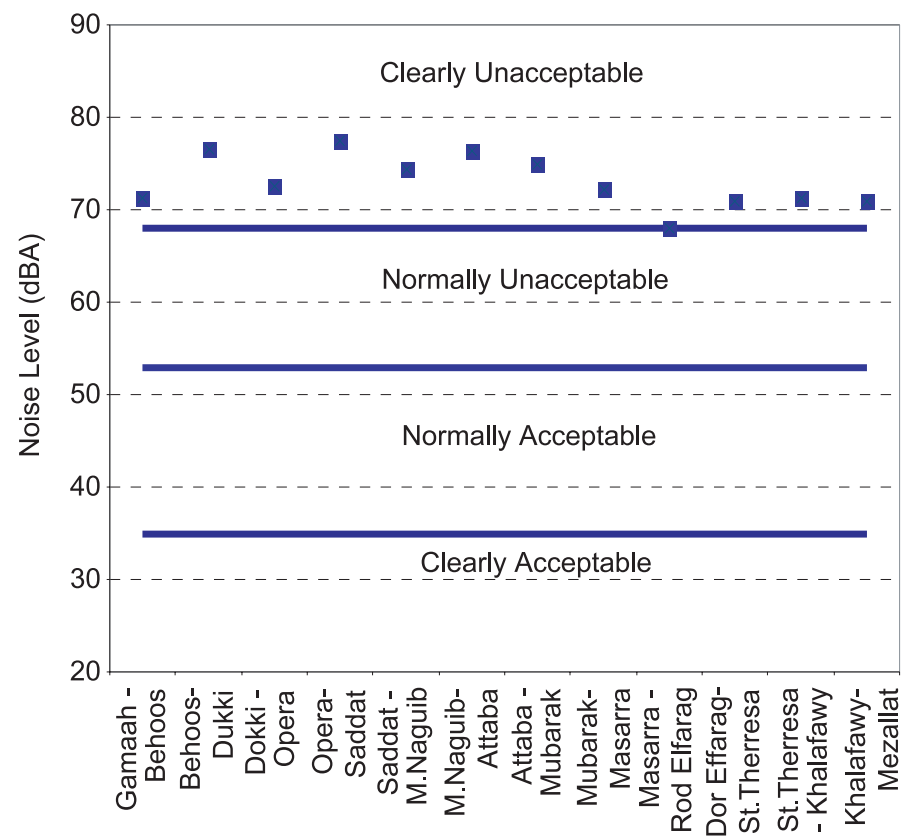

Figure 4. Background noise index $\left(L_{99}\right)$ inside the metro units compared with the criteria for $L_{99}$.

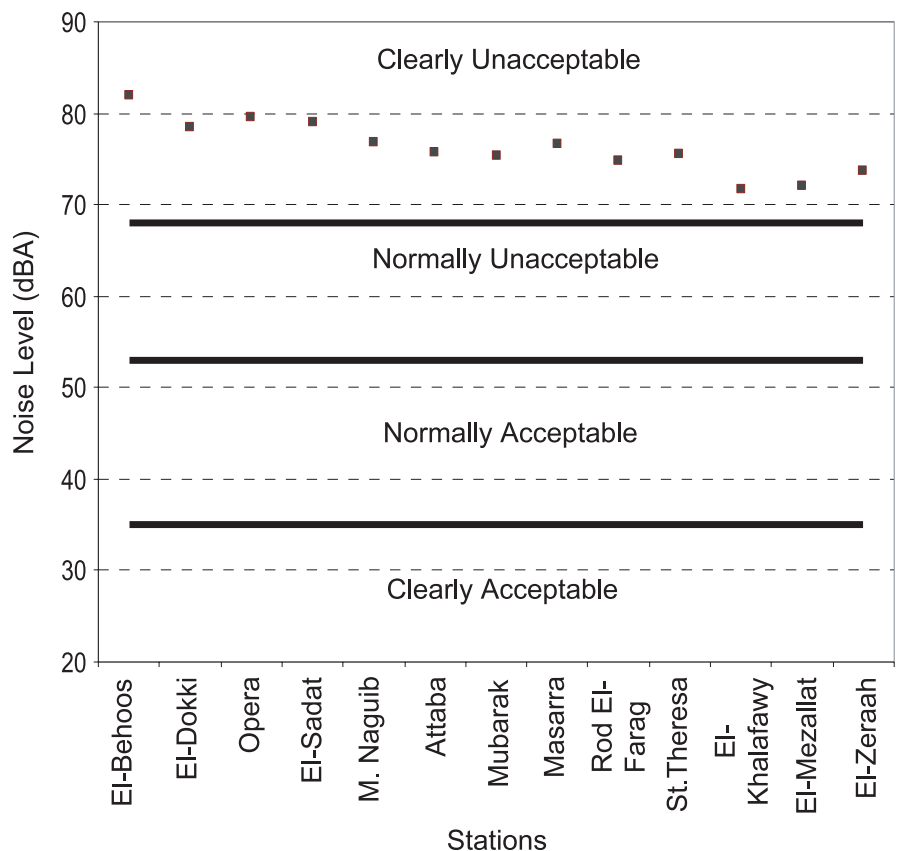

Figure 5. Background noise index $\left(L_{99}\right)$ outside the metro units compared with the criteria for $L_{99}$. 


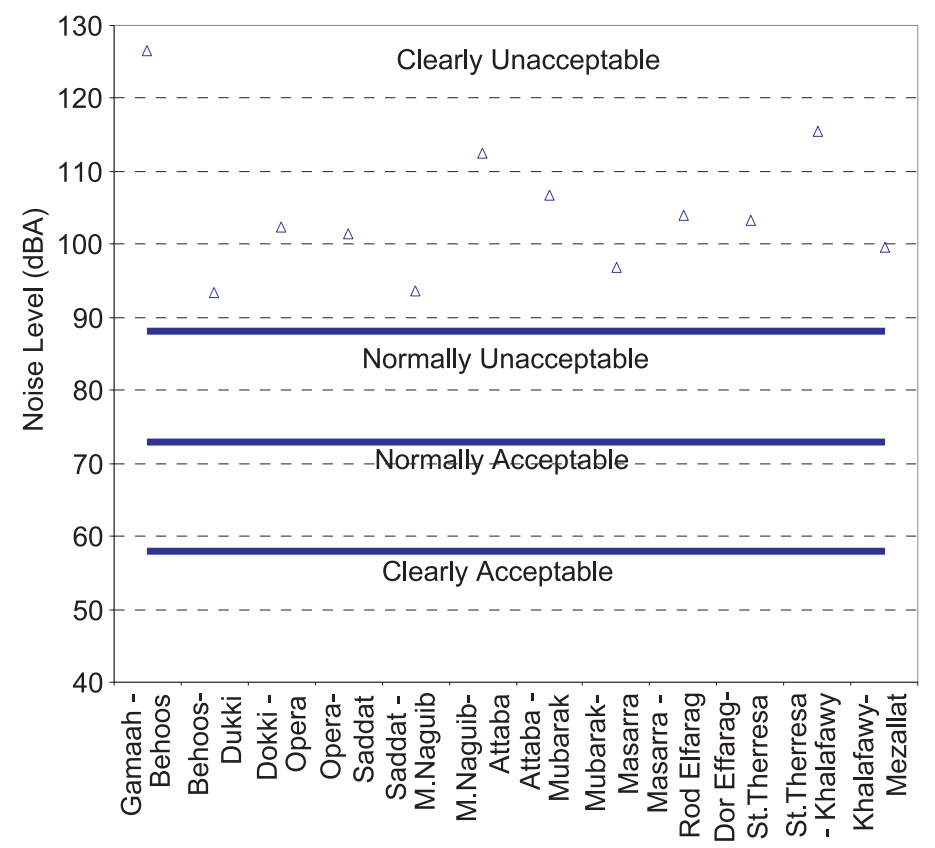

Figure 6. Noise pollution index (LNP) inside the metro units compared with the criteria for LNP.

Figure 6 shows the noise pollution index (LNP), calculated from the measurements of noise levels measured in dBA. inside the metro units between stations, and compared with the criteria adopted by USHUD. The Noise Pollution Index takes into consideration the deviation of the readings from the mean. LNP varies from $93.5 \mathrm{dBA}$ between El-Behoos and El-Dokki stations to $126.4 \mathrm{dBA}$ between El-Gamaah and El-Behoos stations. The comparison using the LNP criteria shows that the noise pollution level along the entire passage in the tunnel is in the range of clearly unacceptable. The increase in LNP between El-Gamaah and El-Behoos stations is due to the entrance of the tunnel, which increase the aerodynamic noise, and also due to the sharp turn of $90^{\circ}$ between these two stations and the mechanical noise of multiple applications of the brakes to reduce speed at the turn, and to the slipping of the wheels on the rails. The increase in LNP between the other stations is due to the increase in the mechanical noise because of multiple use of brakes to reduce the speed and the aerodynamic noise due to the increase of speed.

Figure 7 illustrates the LNP calculated from the measurements of noise levels measured in $\mathrm{dBA}$ outside the units at the station platforms, and compared with the criteria adopted by the USHUD. This figure shows that the LNP varies from $104 \mathrm{dBA}$ at the El-Mezallat station platform to $107.3 \mathrm{dBA}$ at El-Attaba. Comparison of LNP with the criteria shows that the LNP values at all stations are in the range of clearly unacceptable. This is due to the use of the train siren and the application of brakes to stop the trains. The increase of LNP is due to the increases in measured sound levels and standard deviation $(\sigma)$. The increase in $\sigma$ is due to the great difference between the levels recorded for the train siren and brakes compared with the noise of the passengers themselves and the attention-signal sound system. 


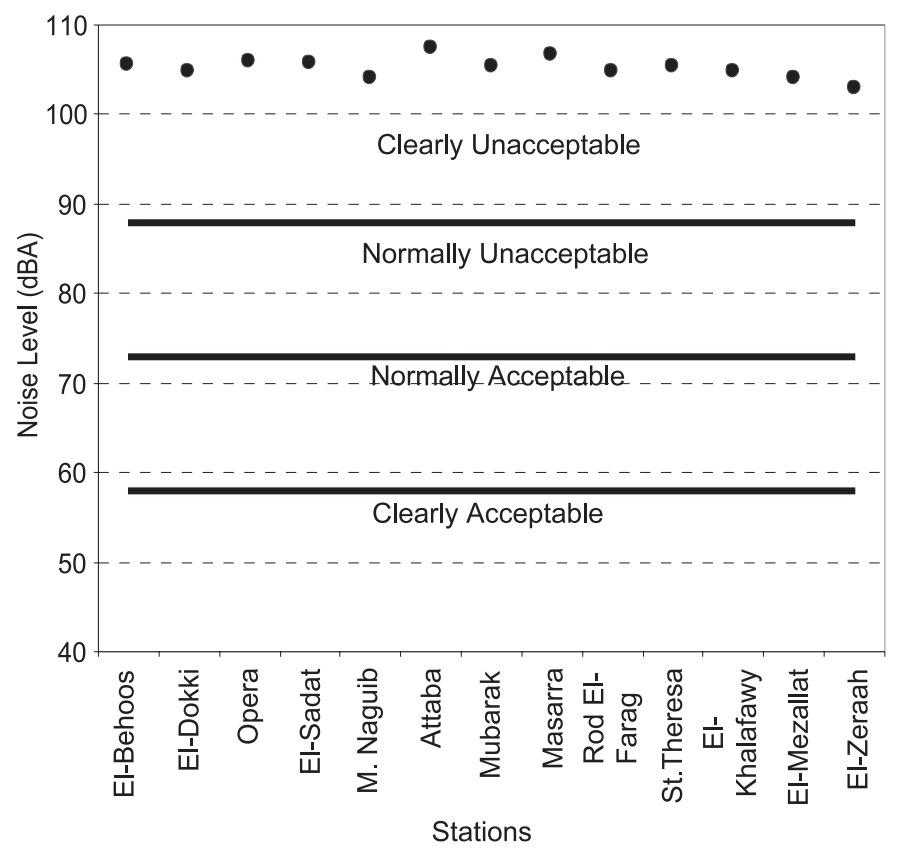

Figure 7. Noise pollution index (LNP) outside the metro units compared with the criteria for LNP.

\section{Conclusions and recommendations}

\subsection{Conclusions}

It is clear from the previous discussions that the noise problem is very significant especially inside the metro units. This increase of noise levels is due to the lack of air in the ventilating system of the units, which causes the passengers to open the side windows to compensate for the required quantity of air. This situation permits the outside noise to enter the units. The side windows are sound-proof windows, which prevent outside noise from entering the units. The closing of the side windows attenuates the noise inside the units by about 20 to $25 \mathrm{dBA}$. The noise outside the metro units is due to the mechanical and aerodynamic noise, which increases by reflection of sound from the tunnel walls. The tunnel has a cylindrical shape which reflects the sound from any source to the centre axis of the tunnel where the trains run.

The noise at the station platforms is due to the application of the air sirens of the trains and the application of the brakes. The increase of noise levels at the platforms are also due to the reflections from the side walls, which are covered with smooth ceramic tiles.

\subsection{Recommendations}

- Increasing the efficiency of the ventilating system inside the metro units to avoid the opening of the side windows.

- Informing the passengers of the importance of closing the side windows.

- Coating the tunnel walls with some kind of sound absorbing materials to decrease the reflection of sound into the metro units.

- Reducing the approach speed of the trains to reduce the time of application of brakes. 
- Replacing the brake lining materials with other more efficient ones to reduce the time of application of brakes

- Changing the smooth ceramic tiles of the station platforms walls by other kinds which can absorb sound to decrease the total noise level at the station platforms.

\section{References}

Alexandre A, Barde J Ph, Lamure C, Langdon F J 1975 Road traffic noise (New York: Halsted)

Don C G, Rees I G 1985 Road traffic sound level distributions. J. Sound Vibr. 100: 41-53

Hastings N A J, Peacock J B 1975 Statistical distributions (London: Butterworth)

HUD 1971 Noise assessment guidelines. US Department of Housing and Urban Development, BBN Report No. 2176, August

HUD 1985 The noise guidebook. US Department of Housing and Urban Development, HUD 953-DPC

Maschke C, Harder J 1998 Environmental medical action required on exposure to noise. Gesundheitswesen 60: 1103-1110

Nagat M A, Risk S A A 1995 study of non-auditory effects of industrial noise. Med. J. Cairo Univ. 63: $155-164$

Nagat M A, Risk S A 2001 Study of the magnitude of environmental noise on pollutant in different sectors of indoor and outdoor. Final Report, 1/6/3/1/2 NRC

Savitz D A, Lio D, Sastre A, Kleckner R C 1999 Magnetic field exposure and cardiovascular disease mortality among electric utility workers. Am. J. Epidemiol. 149: 135-142

Stansfeld F 1998 Loud but not yet clear. Environ. Health Perspect. :100-105 